\title{
Sistem Pakar Identifikasi Kerusakan Smartphone Apple Menggunakan Metode Forward Chaining
}

\author{
Apple Smartphone Damage Identification Expert System Using Forward \\ Chaining Method
}

\author{
Afrizal Yudano Perdana Putra, Brama Wahyu Prabowo, Kusrini \\ Program Studi Magister Teknik Informatika, Fakultas Teknik Informatika \\ Universitas Amikom Yogyakarta
}

E-mail: afrizal7959@students.amikom.ac.id, brama7804@students.amikom.ac.id, kusrini@amikom.ac.id

\begin{abstract}
Abstrak
Kemajuan di bidang teknologi informasi dan sistem cerdas telah melahirkan perangkat lunak seperti sistem pakar yang dilengkapi dengan kemampuan untuk berpikir dan mengembangkan keahlian dalam lingkup bidang tertentu. Pengembangan perangkat lunak atau paket pemrograman komputer dimaksudkan sebagai penyedia informasi sebagai sarana untuk membantu menyelesaikan masalah di bidang spesialisasi tertentu. Penerapan metode forward chaining pada sistem pakar identifikasi kerusakan pada web smartphone berbasis apple dimaksudkan untuk dapat menyederhanakan pengguna smartphone khususnya sistem operasi Ios berbasis apple dalam mengidentifikasi lebih awal jika terjadi kerusakan pada smartphone yang mereka gunakan. Dengan sistem pakar ini para pengguna diharapkan mendapatkan informasi tentang jenis-jenis gejala kerusakan yang terjadi ketika smartphone mangalami kerusakan dan bisa mendapatkan kemudahan dalam mengidentifikasi kerusakan apa yang mungkin ia alami.
\end{abstract}

Kata Kunci_sistem pakar, smartphone, apple

\begin{abstract}
Progress in the field of information technology and intelligent systems has given rise to software such as expert systems that are equipped with the ability to think and develop expertise within the scope of a particular field. The development of software or computer programming packages is intended as an information provider as a means to help solve problems in certain areas of specialization. The application of the forward chaining method on the expert system of damage identification on the applebased smartphone web is intended to be able to simplify smartphone users, especially the Apple-based Ios operating system in identifying earlier if there is damage to the smartphone they use. With this expert system users are expected to get information about the types of symptoms of damage that occur when the smartphone is damaged and can get ease in identifying what damage it might experience.
\end{abstract}

Keywords - expert systems, smartphone, apple

\section{Pendahuluan}

pengembangan perangkat lunak atau paket program komputer yang ditujukan sebagai penyedia informasi sebagai sarana bantu dalam pemecahkan masalah di bidang-bidang spesialisasi tertentu seperti sains, perekayasaan, matematika, kedokteran, pendidikan dan lain sebagainya. Kemajuan teknologi dalam bidang komunikasi sangat berkembang pesat pada era modern saat ini. Salah satu perangkat komunikasi yang sangat berkembang adalah smartphone, hampir setiap orang didunia memiliki sebuah smartphone untuk keperluan pribadi sehari-hari mereka. Kenyataan sekarang ini bahwa kerusakan pada sebuah smartphone sering kali mengganggu pengguna smartphone, sehingga penggunanya harus membawa smartphone tersebut ke jasa service smartphone untuk mengetahui kerusakan apa yang terjadi pada perangkat tersebut. Waktu perbaikan yang habis terpakai selama smartphone pengguna ditempat service juga dapat menyita waktu pengguna, belum juga biaya yang akan dikeluarkan untuk memperbaikinya, serta jarak yang ditempuh ketempat service smartphone mungkin sangatlah jauh.

Dari keadaan yang telah diuraikan diatas menjadi acuan dan tolak ukur untuk mengembangkan sebuah sistem yang dapat membantu memecahkan masalah seperti seorang ahli dengan cara memberi 
kemungkinan informasi dibidangnya, dari permasalahan tersebut penulis akan mencoba membuat sebuah sistem pakar sesuai permasalahan yang muncul.

Dengan pertimbangan dalam pemilihan metode yang digunakan, maka terpilihlah metode forward chaining yang dirasa cocok dekat dengan permasalahan kerusakan pada smartphone keluaran apple. Dari sekian banyak metode, penulis lebih memilih metode forward chaining karna memiliki struktur yang beruntut sehingga memudahkan pengguna dalam mendapatkan informasi kesimpulan permasalahan yang sedang dialami, supaya permasalahan tersebut lebih mudah ditelusuri, cukup dengan menginputkan gejala-gejala kerusakan pada sistem, maka permasalahan kerusakan pada smartphone dapat diketahui.

Penelitian terdahulu oleh Juniar Lestari yang berjudul Analisis Sistem Deteksi Kerusakan Komputer Dengan Menggunakan Metode Forward Chaining tahun 2016. Membahas adanya sebuah sistem yang akan membantu semua pengguna komputer, baik yang pemula maupun yang telah menguasai ilmu komputer, untuk dapat mengetahui jenis kerusakan yang terjadi pada komputer yang digunakan.

\section{Metode Penelitian}

Metode Forward Chaining, erupakan metode pencarian beruntut dari awal sampai akhir yang memulai proses pencarian dari sekumpulan data, dari data-data tersebut dicari suatu kesimpulan serta mencari solusi dari permasalahan yang dihadapi. Dengan cara mencocokan data tersebut dengan bagian IF dari rules IF-THEN. Bila ada fakta yang cocok dengan bagian IF, maka rule tersebut dieksekusi. penelusuran dimulai dari fakta yang ada lalu bergerak maju melalui premis premis untuk menuju ke kesimpulan / bottom up reasoning.

\subsubsection{Gambar dan Tabel}

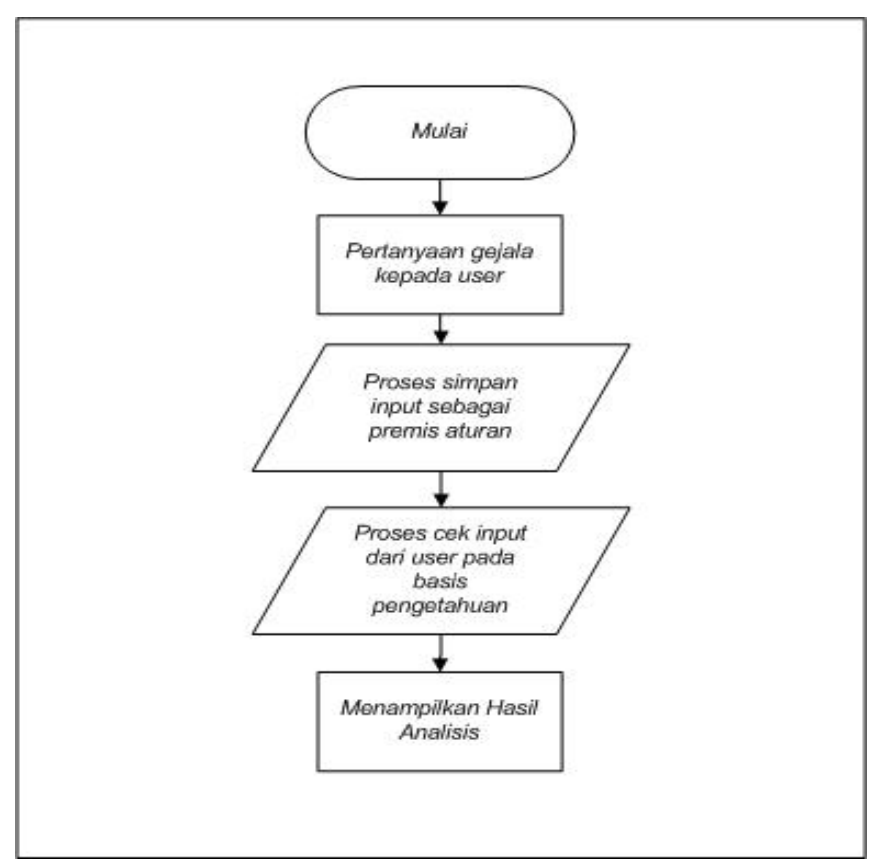

Gambar 1. Alur Penelitian 


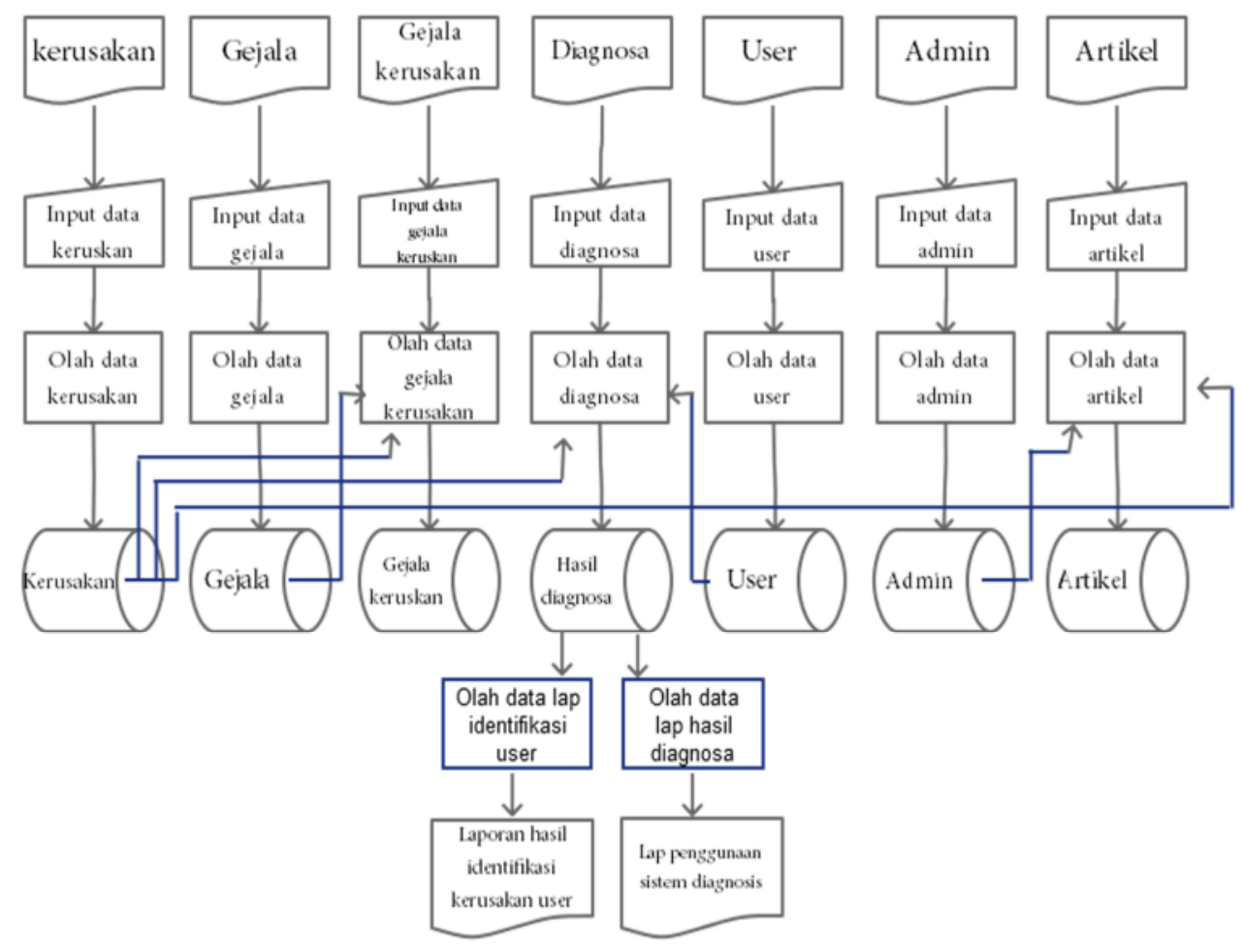

Gambar 2. Flowchart Sistem

Tabel dalam basis data secara umum digunakan untuk menyimpan informasi yang dibutuhkan dan dibuat didalam basis data sistem. Ada 7 tabel yang dibuat dalam sistem ini, yaitu table admin, user, gejala, diagnosis, gejala_kerusakan, kerusakan, artikel

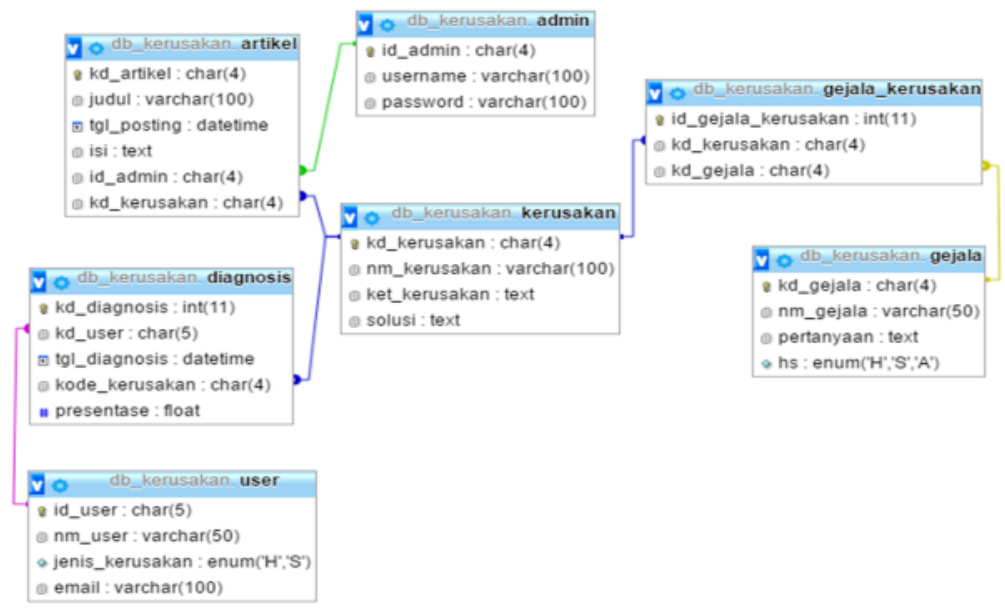

Gambar 3. Relasi Antar Tabel

Rancangan Interface 


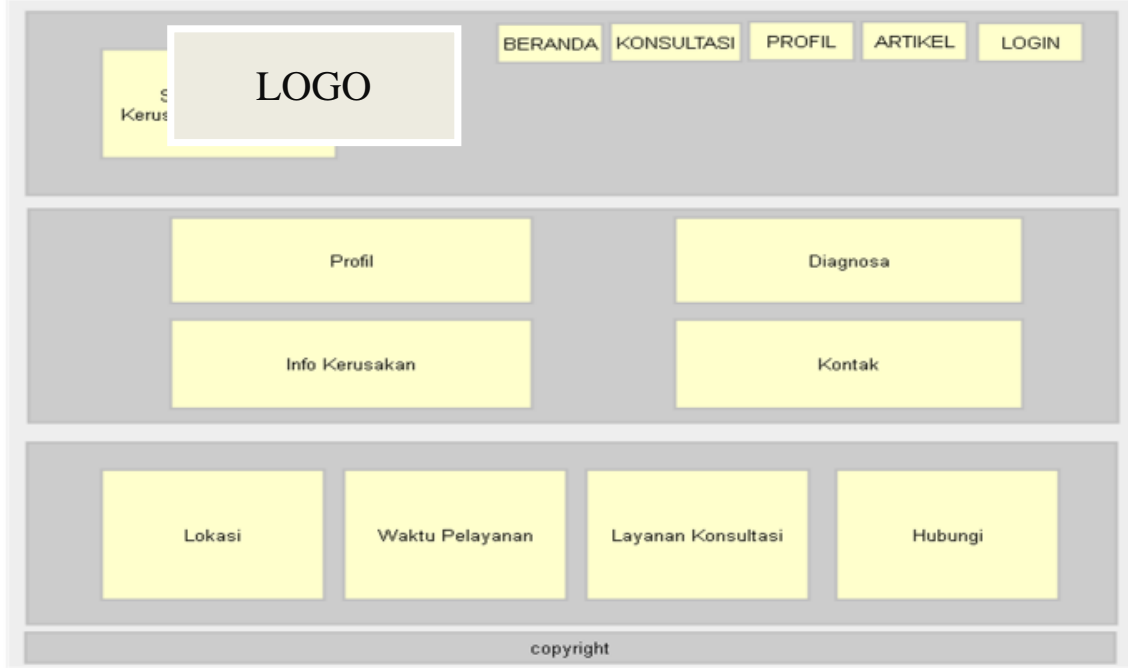

Gambar 4. Perancangan Interface Home User

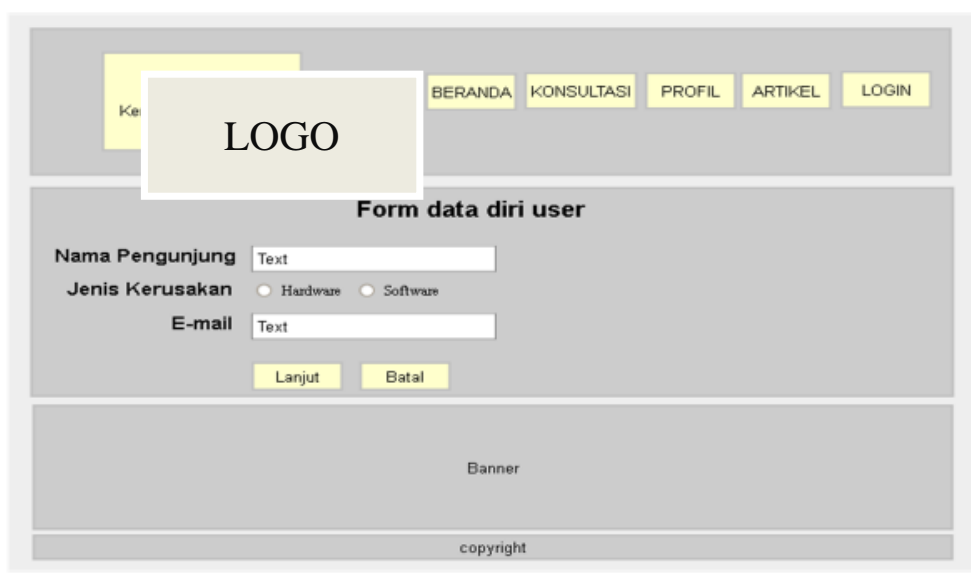

Gambar 5. Perancangan Interface Data User Identifikasi

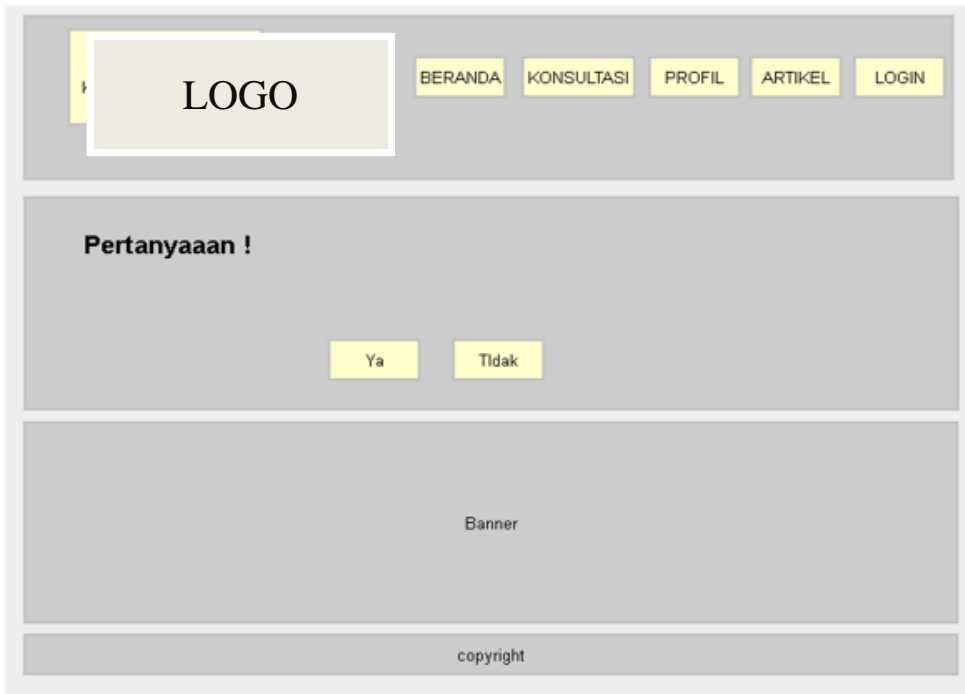

Gambar 6. Perancangan Interface Identifikasi 


\subsubsection{Rumus Matematika}

Pada kasus penelusuran pohon keputusan terdapat masalah, yaitu tidak semua gejala terdeteksi sesuai fakta di lapangan untuk itu penulis memberikan perhitungan persen pada sistem, dimana jika suatu kerusakan mempunyai nilai lebih dari 50\% maka kerusakan tersebut terdeteksi, dan jika kurang dari 50\% maka kerusakan diragukan.

Cara perhitungan yang digunakan pada proses penarikan kesimpulan pada saat identifikasi kerusakan smartphone apple adalah sebagai berikut :

$\frac{\text { data input }}{\text { data gejala }} \times 100 \%=\cdots \cdots \cdots$

Keterangan :

- Data input = data saat input kerusakan di sistem dan terpenuhi pada data gejala di database.

- Data gejala = total kerusakan yang terpilih pada gejala kerusakan di database

\section{Hasil dan Pembahasan}

A. Black box Testing validasi

1. Jika username/password tidak diisi

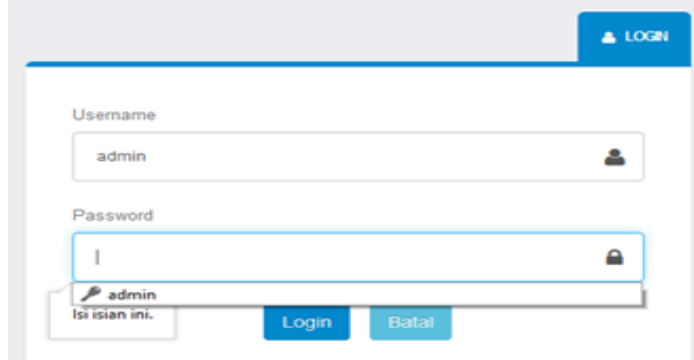

Gambar 7. Validasi Login Tidak Diisi

Begitu juga saat admin mengisi username/password namun usename/password tidak valid maka sistem akan memunculkan pesan kesalahan.

2. Jika Username/password tidak valid

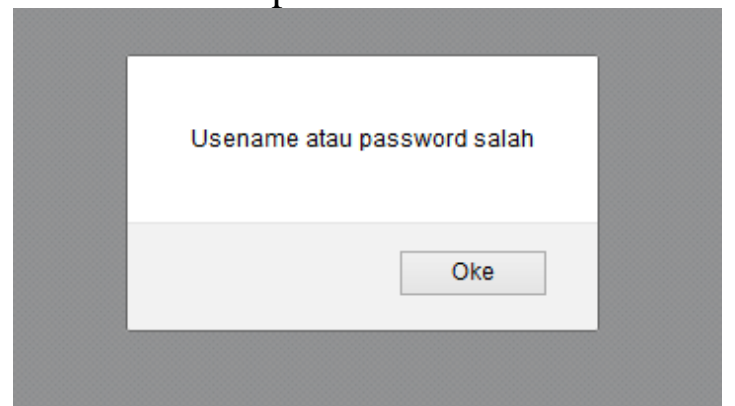

Gambar 8. Tampilan Peringatan Jika Login Tidak Valid

B. Black box Testing Fitur User 
1. Menu Utama Pengguna

Tabel 1. Uji Menu Utama Home

\begin{tabular}{|l|l|}
\hline Metode Pengujian & User mengakses menu Home \\
\hline Hasil Pengetahuan & $\begin{array}{l}\text { Konten beranda akan tampil (beberapa fitur } \\
\text { menu) }\end{array}$ \\
\hline Kesimpulan & Sukses \\
\hline
\end{tabular}

2. Menu Konsultasi

Tabel 2. Uji Menu Konsultasi

\begin{tabular}{|l|l|}
\hline Metode Pengujian & User mengakses menu konsultasi \\
\hline Hasil Pengujian & $\begin{array}{l}\text { Konten menu konsultasi akan tampil dan user } \\
\text { dapat memilih gejala yang dialami dengan } \\
\text { mengklik "ya" jika merasakan gejala dan } \\
\text { "tidak" jika tidak merasakan gejala. }\end{array}$ \\
\hline Kesimpulan & Sukses \\
\hline
\end{tabular}

3. Menu Artikel

Tabel 3. Uji Menu Artikel

\begin{tabular}{|l|l|}
\hline Metode Pengujian & User mengakses menu artikel \\
\hline Hasil Pengujian & $\begin{array}{l}\text { Konten menu artikel menampilkan artike } \\
\text { mengenai kerusakan smartphone apple dan } \\
\text { juga informasi tentang smartphone itu sendiri. }\end{array}$ \\
\hline Kesimpulan & Sukses \\
\hline
\end{tabular}

C. Black box Testing Identifikasi Kerusakan

1. IC PA

Tabel 4. Validasi Kerusakan IC PA

\begin{tabular}{|l|l|}
\hline Kerusakan & K001 - IC PA \\
\hline Gejala & 1. Smartphone tidak bisa menyala \\
& 2. Smartphone tidak ada sinyal \\
& 3. Smartphone gagal telpon \\
\hline
\end{tabular}




\begin{tabular}{|l|l|l|}
\hline Screen Shot & \multicolumn{2}{|l|}{ Gejala Yang Didapatkan } \\
\cline { 2 - 3 } & G001 & Smartphone tidak bisa menyala \\
\hline & G002 & Smartphone tidak ada sinyal \\
\hline & G008 & Smartphone gagal telepon \\
\hline & Kesimpulan & IC PA (Power Ampilifier) \\
\hline Presentase & 100\% \\
\hline Kesimpulan & Berhasil & \\
\hline
\end{tabular}

2. IC POWER

Tabel 5. Validasi Kerusakan IC POWER

\begin{tabular}{|c|c|c|}
\hline Kerusakan & \multicolumn{2}{|c|}{ K002 - IC POWER } \\
\hline Gejala & \multicolumn{2}{|c|}{$\begin{array}{l}\text { 1. Smartphone tidak bisa menyala } \\
\text { 2. Smartphone tidak ada sinyal } \\
\text { 3. Muncul tulisan insert SIM di layar } \\
\text { Smartphone } \\
\text { 4. Smartphone tidak bisa di charger }\end{array}$} \\
\hline \multirow[t]{7}{*}{ Screen Shot } & \multicolumn{2}{|c|}{ Gejall Yang Diddpatktan } \\
\hline & 6001 & Snatpronen etak bisa menylala \\
\hline & 6002 & Snatphonent trak ada sinyal \\
\hline & 6005 & Snartphone trakk bisa a cicharger \\
\hline & 6009 & Muncul tulisan inset SMM dil layar S Smatrohone \\
\hline & Kesimpulan & Ic Power \\
\hline & Presentase & $100 \%$ \\
\hline Kesimpulan & \multicolumn{2}{|c|}{ Berhasil } \\
\hline
\end{tabular}

3. Driver LCD

Tabel 6. Validasi Kerusakan Driver LCD

\begin{tabular}{|l|l|}
\hline Kerusakan & K003 - Driver LCD \\
\hline Gejala & $\begin{array}{l}\text { 1. Smartphone masih bisa menyala } \\
\text { 2. LCD Smartphone bergaris } \\
\end{array}$ \\
& $\begin{array}{l}\text { 3. LCD Smartphone blank } \\
\end{array}$ \\
\hline
\end{tabular}




\begin{tabular}{|l|l|l|}
\hline Screen Shot & \multicolumn{2}{|l|}{ Gejala Yang Didapatkan } \\
\cline { 2 - 3 } & G003 & Smartphone masih bisa menyala \\
\hline G006 & LCD Smartphone bergaris \\
\hline G012 & LCD Smartphone blank \\
\hline Kesimpulan & Driver LCD \\
\hline Presentase & $100 \%$ \\
\hline Kesimpulan & Berhasil & \\
\hline
\end{tabular}

4. IC RAM

Tabel 7. Validasi Kerusakan IC RAM

\begin{tabular}{|c|c|c|}
\hline Kerusakan & \multicolumn{2}{|c|}{ K004 - IC RAM } \\
\hline Gejala & \multicolumn{2}{|c|}{$\begin{array}{l}\text { 1. Smartphone tidak ada sinyal } \\
\text { 2. Smartphone masih bisa menyala } \\
\text { 3. Smartphone mengalami restart yang sangat } \\
\text { lama } \\
\text { 4. Smartphone gagal telepon } \\
\text { 5. Smartphone mengalami hang menu }\end{array}$} \\
\hline \multirow[t]{8}{*}{ Screen Shot } & \multicolumn{2}{|c|}{ Gejala Yang Didapatkan } \\
\hline & 6002 & Smartphone tidak ada sinyal \\
\hline & 6003 & Smartphone masih bisa menyala \\
\hline & 6007 & Smartphone mengalami restaty yang sangatl Ima \\
\hline & 6008 & Smathonone gagal telepon \\
\hline & 6015 & Smartphone mengalami hang menu \\
\hline & Kesimpulan & IC RAM \\
\hline & Presentase & $100 \%$ \\
\hline Kesimpulan & Berhasi & \\
\hline
\end{tabular}

5. IC CPU

Tabel 8. Validasi Kerusakan IC CPU

\begin{tabular}{|l|l}
\hline Kerusakan & K005 - IC CPU
\end{tabular}




\begin{tabular}{|c|c|c|}
\hline Gejala & \multicolumn{2}{|c|}{$\begin{array}{l}\text { 1. Smartphone tidak ada sinyal } \\
\text { 2. Smartphone masih bisa menyala } \\
\text { 3. Smartphone tiba-tiba mati sendiri } \\
\text { 4. Smartphone mengalami blank screen }\end{array}$} \\
\hline \multirow[t]{7}{*}{ Screen Shot } & \multicolumn{2}{|c|}{ Gejala Yang Didapatkan } \\
\hline & G002 & Smartphone tidak ada sinyal \\
\hline & G003 & Smartphone masih bisa menyala \\
\hline & G011 & Smartphone tiba-tiba mati sendiri \\
\hline & G013 & Smartphone mengalami blank screen \\
\hline & Kesimpulan & IC CPU \\
\hline & Presentase & $100 \%$ \\
\hline Kesimpulan & \multicolumn{2}{|l|}{ Berhasil } \\
\hline
\end{tabular}

6. Bootloop

Tabel 9. Validasi Kerusakan Bootloop

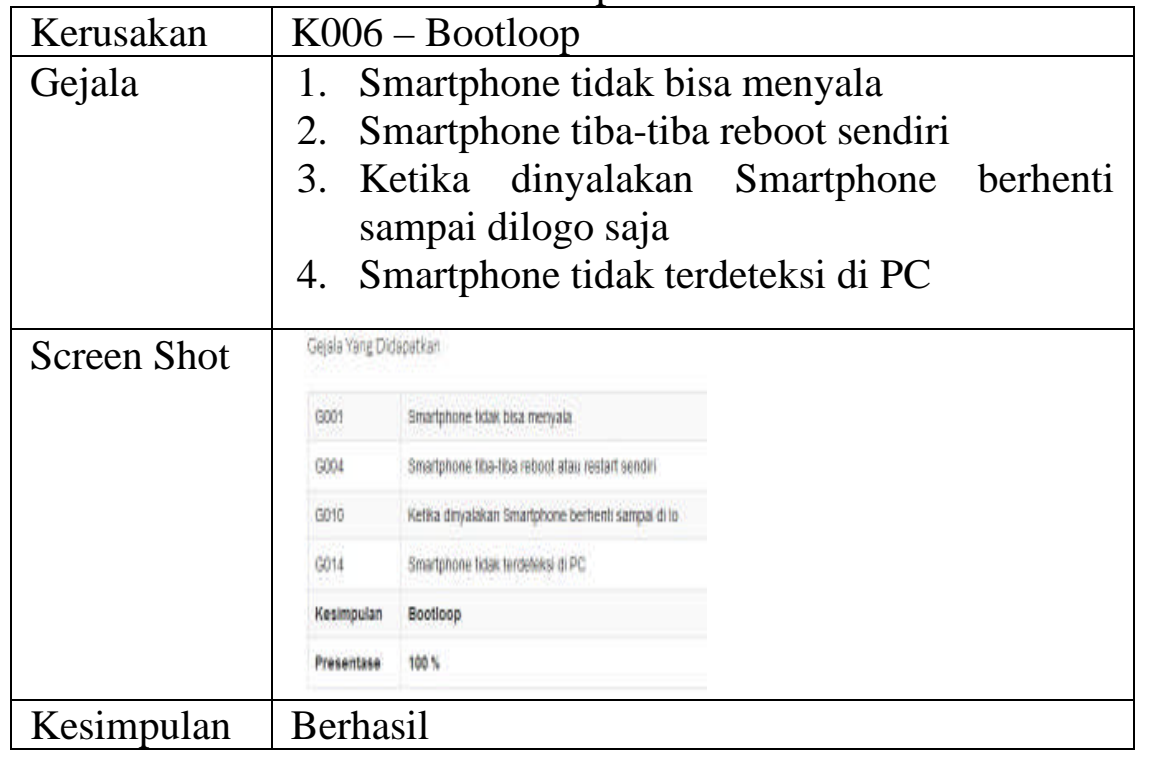

7. Softbrick

Tabel 10. Validasi Kerusakan Softbrick

\begin{tabular}{l|l}
\hline Kerusakan & K007 - Softbrick
\end{tabular}




\begin{tabular}{|c|c|c|}
\hline Gejala & \multicolumn{2}{|c|}{$\begin{array}{l}\text { 1. Smartphone masih bisa menyala } \\
\text { 2. Smartphone tiba-tiba reboot atau restart } \\
\text { sendiri } \\
\text { 3. Ketika dinyalakan Smartphone berhenti } \\
\text { samapai dilogo saja } \\
\text { 4. Smartphone mengalami blank screen } \\
\text { 5. Smartphone mengalami restart yang } \\
\text { sangat lama }\end{array}$} \\
\hline \multirow[t]{8}{*}{ Screen Shot } & \multicolumn{2}{|c|}{ Géala Yang Didapattlan } \\
\hline & & Smathonon masibi bisa menyala \\
\hline & 6004 & 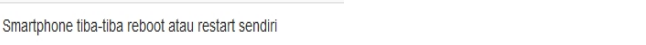 \\
\hline & 6007 & Smatpronen mengalamm restatry yang sangat lama \\
\hline & 6010 & 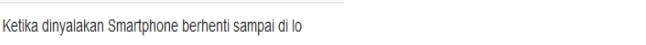 \\
\hline & & Smatphonen energalan bear screen \\
\hline & Kesimpulan & Sottorick \\
\hline & Presentase & 100\% \\
\hline Kesimpulan & \multicolumn{2}{|c|}{ Berhasil } \\
\hline
\end{tabular}

8. Hardbrick

Tabel 11. Validasi Kerusakan Hardbrick

\begin{tabular}{|c|c|c|}
\hline Kerusakan & \multicolumn{2}{|c|}{ K008 - Hardbrick } \\
\hline Gejala & \multicolumn{2}{|c|}{$\begin{array}{l}\text { 1. Smartphone tidak bisa menyala } \\
\text { 2. Smartphone tidak bisa di charger } \\
\text { 3. Smartphone tiba-tiba mati sendiri } \\
\text { 4. Smartphone tidak terdeteksi di PC } \\
\text { 5. Smartphone mati total }\end{array}$} \\
\hline \multirow[t]{8}{*}{ Screen Shot } & \multicolumn{2}{|c|}{ Gejala Yang Didapatkan } \\
\hline & G001 & Smartphone tidak bisa menyala \\
\hline & G005 & Smartphone tidak bisa dic charger \\
\hline & G011 & Smartphone tiba-tiba mati sendiri \\
\hline & G014 & Smartphone tidak terdetetesi di PP \\
\hline & G016 & Smarphone matit total \\
\hline & Kesimpulan & Hardbrick \\
\hline & Presentase & $100 \%$ \\
\hline Kesimpulan & \multicolumn{2}{|l|}{ Berhasil } \\
\hline
\end{tabular}

\section{White box Testing}

Pada sistem identifikasi kerusakan smartphone apple semua fungsi berjalan dengan normal dan sistem menampilkan output yang telah dirancang sebelumnya. Tidak ada error atau masalah dalam proses penggunaan sistem ini, maka sistem ini dinyatakan berhasil. 


\section{Kesimpulan}

Maka dapat diambil kesimpulan antara lain :

1. Perbuatan sistem identifikasi kerusakan smartphone apple dinyatakan berhasil.

2. Sistem mampu memberi informasi tentang identifikasi kerusakan smartphone dengan cara mengolah data yang diinputkan untuk manarik kesimpulan.

3. Sistem membantu dalam identifikasi awal dan menyimpulkan kemungkinan kerusakan awal pada smartphone tanpa harus datang ke tempat service ketika terjadi kerusakan pada smartphone apple.

4. Metode forward chaining yang diterapkan mampu dalam membantu sistem dalam identifikasi kerusakan smartphone apple yang baik sebagai deteksi awal kerusakan.

\section{Saran}

Saran dalam penelitian ini adalah melakukan pengembangan platform dari web ke platform lain seperti android dan Ios itu sendiri.

\section{Ucapan Terima Kasih}

Penulis mengucapkan terima kasih kepada Allah SWT yang telah memberi rahmat sehingga penulisan jurnal ini berjalan dengan lancar, kedua orang tua yang telah memberi dukungan financial, dan orang - orang terdekat yang telah mendukung pengerjaan penelitian ini.

Secara khusus, peneliti menyampaikan rasa terima kasih yang mendalam kepada dosen pembimbing yang telah memberikan bimbingan dan arahannya agar terselesaikannya jurnal penelitian ini.

\section{Daftar Pustaka}

[1] Lestari, Juniar. 2016. Analisis Sistem Deteksi Kerusakan Komputer Dengan Menggunakan Metode Forward Chaining. Program Studi Sistem Informasi, STMIK AKBA.

[2] Turban, Efraim. 2005. Decision Support System and expert Systems. Yogyakarta: ANDI

[3] Daihani, Dadan Umar. 2001. Komputerisasi Pengambilan Keputusan. Jakarta: Elex Media Komputindo.

[4] yuhefizar. 2013. Cara mudah dan murah membangun dan mengelola website. Yogyakarta: Grahailmu.

[5] Handayani, Dewi. 2009. Analisis forward Chaining Dan Penalaran Inexact Pada Rule Based Expert System. IT Telkom

[6] Hartono, Jogiyanto, 2005, Analisis dan Desain Sistem Informasi, Andi Offset, Yogyakarta

[7] Simarmata, Janner dan Prayudi, Irman.2006. Basis Data. Penerbit ANDI. Yogyakarta

[8] Nidhra, Srinivas, and Dondeti, Jagruthi. 2012. Blackbox and Whitebox Testing Techniques - A Literature Review, International Journal of Embedded Systems and Applications (IJESA) Vol.2, No.2, June 2012. 